\title{
A VALORAÇÃO NAS SENTENÇAS COM ADJUNTOS MODAIS DO CONTO "GRACE", DE JOYCE, E DE DUAS DE SUAS REINSTANCIAÇÕES PARA O PORTUGUÊS DO BRASIL
}

\author{
Roberta Rego Rodrigues 1 \\ 1Universidade Federal de Pelotas, Pelotas, Rio Grande do Sul, Brasil
}

\begin{abstract}
Resumo: A Valoração é um sistema semântico-discursivo interpessoal que prevê significados de Atitude, Comprometimento e Gradação (Martin and White). Este artigo tem por objetivo investigar de forma geral os três sistemas valorativos nas sentenças com Adjuntos Modais do conto "Grace”, de James Joyce (a), e em duas Reinstanciações para o português do Brasil, uma feita por José Roberto O'Shea (Joyce b) e a outra produzida por Guilherme da Silva Braga (Joyce c). Foi utilizada uma planilha eletrônica com três abas para a classificação e a quantificação de dados. Os resultados mostram que os Adjuntos Modais são importantes para a identificação de significados valorativos. Pode-se concluir que as categorias mais frequentes nos contos são Julgamento, Heteroglossia e Força.
\end{abstract}

Palavras-chave: Reinstanciação Interlinguística; Valoração; Adjuntos Modais; Contos

\section{APPRAISAL IN SENTENCES WITH MODAL ADJUNCTS OF THE SHORT STORY "GRACE", BY JOYCE, AND OF TWO OF ITS REINSTANTIATIONS INTO BRAZILIAN PORTUGUESE}

\begin{abstract}
Appraisal is an interpersonal discourse semantic system that presupposes meanings of Attitude, Engagement, and Graduation (Martin and White). This paper aims to explore in general the three appraising systems in the sentences with Modal Adjuncts of the short story "Grace", by James Joyce (a), and in two of its Re-instantiations into Brazilian
\end{abstract}


Portuguese, one by José Roberto O'Shea (Joyce b), and the other one by Guilherme da Silva Braga (Joyce c). The use of a three-tabbed spreadsheet was made for data classification and quantification. Results point out that Modal Adjuncts are important to the identification of appraising meanings. It can be concluded that the most frequent categories in the short stories are Judgement, Heteroglossia, and Force.

Keywords: Interlinguistic Re-instantiation; Appraisal; Modal Adjuncts; Short Stories

\section{Introdução}

Ao levar em conta que em geral somos ineficientes para retomar o significado relacional, ou seja, o significado das palavras entre si, quando exteriorizamos sentimentos de forma consciente, Martin (apud Rodrigues) comenta que, de modo oposto, uma/um tradutora/tradutor atua de forma relacional, ao traduzir textos de uma língua para outra, com o intuito de encontrar as melhores escolhas tradutórias.

Uma das perspectivas na interface dos Estudos dos Tradução com a Linguística Sistêmico-Funcional é compreender o Texto Traduzido como uma Reinstanciação Interlinguística (Souza b). A autora não ignora o conceito de equivalência e defende que, além da hierarquia "Realização", as outras hierarquias, tais como "Instanciação" e "Individuação", devam ser também consideradas. Mais especificamente, um Texto Traduzido visto como uma Reinstanciação Interlinguística pressupõe que um Texto Traduzido recria o potencial de significado de um Texto Fonte.

Souza (b) aplica seu modelo de Tradução como Reinstanciação Interlinguística com o respaldo do sistema Valoração (Martin and White). Segundo Martin and White, a Valoração vincula-se à Semântica do Discurso e agrega ferramentas linguísticas importantes para a investigação da Atitude, do Comprometimento e da Gradação na linguagem.

Este artigo tem por objetivo investigar de forma geral a Valoração nas sentenças com Adjuntos Modais do conto "Grace", de Ja- 
mes Joyce (a), e em duas de suas Reinstanciações para o português do Brasil, uma feita por José Roberto O'Shea (Joyce b) e a outra produzida por Guilherme da Silva Braga (Joyce c). Busca-se, outrossim, pesquisar cada Texto Traduzido em comparação ao Texto Fonte bem como as Reinstanciações Interlinguísticas entre si.

Este artigo torna-se útil para estabelecer diálogo com outros trabalhos que apresentam temas semelhantes e para suscitar possíveis discussões acerca dessa perspectiva na interface supracitada.

Levando-se em conta as sentenças com Adjuntos Modais, as seguintes perguntas de pesquisa norteiam este trabalho.

1. Como se manifesta a Valoração em cada Reinstanciação Interlinguística, em cotejo com o Texto Fonte?

2. Como se manifesta a Valoração comparando-se as Reinstanciações Interlinguísticas entre si?

Cumpre salientar que essas perguntas de pesquisa serão respondidas com o apoio do Referencial Teórico e da Metodologia adotada.

Além desta Introdução, este artigo apresenta seções que expõem a teoria eleita; os procedimentos metodológicos empregados; os dados analisados e discutidos; um agradecimento; palavras de encerramento; e a bibliografia.

Em seguida é mostrado o arcabouço teórico defendido neste artigo.

\section{Referencial Teórico}

Esta seção traz conceitos relativos a uma perspectiva dentro da interface dos Estudos da Tradução com a Linguística SistêmicoFuncional, assim como a um dos sistemas vinculado à semântica do discurso, qual seja, a Valoração. 


\subsection{Tradução como Reinstanciação Interlinguística}

A "Realização" é uma hierarquia de abstração, que recodifica um nível de significado em um outro. Já a "Instanciação" é uma hierarquia de generalização, que acrescenta o potencial de significado de uma cultura a instâncias de uso. A primeira hierarquia tem sido a mais investigada no âmbito da Linguística Sistêmico-Funcional. Na hierarquia "Realização", o estrato "gênero" sobrepõese ao estrato "registro", que, por sua vez, está acima do estrato "semântica do discurso". Esse estrato antepõe-se à "léxico-gramática" que, finalmente, se coloca antes do estrato grafológico. $\mathrm{Na}$ hierarquia "Instanciação", desloca-se do sistema em direção aos sub-potenciais de gênero e de registro, por meio de tipos de texto, o que resulta em leituras do potencial de significado propiciadas por textos individuais (Martin b).

Segundo Souza (a), a hierarquia "Realização" situa-se no princípio da hierarquia "Instanciação". Por esse motivo, consoante a autora, Martin (e.g. b) defende que todos os estratos instanciam, visto que os mesmos contribuem para a construção de um texto.

Além da "Realização" e da "Instanciação", há a hierarquia "Individuação", que se relaciona com o reservatório de significados presentes em uma cultura e com a maneira pela qual uma/um usuária/o da língua utiliza esse reservatório a partir de seu repertório. Em relação ao repertório, existem as regras de reconhecimento e de realização (recognition and realisation rules). As primeiras regras possibilitam que as/os usuárias/os da língua depreendam o conteúdo de contextos e as segundas oportunizam a essas/esses usuárias/os a produção de textos e práticas culturalmente específicos (Bernstein apud Martin b).

Hood investiga com fins linguístico-pedagógicos a escrita acadêmica de estudantes de Ensino Médio e de Ensino Superior na Austrália. A autora observa como se dá a Reinstanciação Intralinguística dessas/desses estudantes quando elas/ eles, a partir de um texto-base (source text), fazem anotações (notes), que são transformadas em um resumo (summary text). Hood constata que houve 
mudanças de significados textuais, interpessoais e ideacionais durante o andamento das atividades. Segundo a autora, isso contribui para mostrar como esses textos acadêmicos podem ser escritos.

No domínio dos Estudos da Tradução, Souza (b) preconiza o conceito de Reinstanciação Interlinguística a fim de deslocar o foco da hierarquia "Realização", que também é a mais favorecida na interface dessa interdisciplina com a Linguística Sistêmico-Funcional, como dito anteriormente. Sem desconsiderar a concepção de equivalência, a autora localiza a tradução nas três hierarquias, quais sejam, "Realização", "Instanciação" e "Individuação", salientando que um Texto Traduzido reelabora o potencial de significado de um Texto Fonte. Conforme Souza (b), essa reelaboração torna-se possível em função da leitura que a/o tradutora/tradutor faz do Texto Fonte. E, em consequência disso, tal leitura é justificada através dos repertórios dessas/desses profissionais nas línguas e culturas envolvidas Souza (b). Baseando-se em Martin and White, Souza (b) acredita que o Texto Traduzido pode ter uma leitura tática, condescendente ou resistente do Texto Fonte. Isso dependerá dos ambientes de tradução compreendidos, uma vez que o tipo de leitura poderá modificar-se no decorrer do processo tradutório. Souza (b) utiliza ainda o sistema Valoração (Martin and White) a fim de aplicar seu modelo de Tradução como Reinstanciação Interlinguística.

\subsection{Semântica do Discurso}

Martin (a) faz uso da Gramática Sistêmico-Funcional a fim de questionar a estrutura textual, ao priorizar o texto em vez da oração. Segundo o autor, a semântica do discurso tem o intuito de investigar o contraste entre a gramática e a semântica de uma forma estratificada, isto é, entre os subsídios orientados à oração e ao texto, no que concerne a questões de significado.

Ao examinar o significado para além da oração com o propósito de estabelecer uma conexão com o contexto social, Martin and Rose propõem sistemas vinculados às metafunções textual, interpessoal e ideacional. São eles, respectivamente: 
1. A Identificação que indica como rastrear os Participantes e a Periodicidade que mostra como a informação flui através de ondas textuais.

2. A Valoração que diz respeito à maneira pela qual as atitudes são negociadas e a Negociação que se relaciona a interações dialógicas.

3. A Ideação que informa como a experiência é construída e a Conjunção que trata das ligações lógicas.

A pesquisa dos autores insere-se na Análise do Discurso de orientação Anglófona e pode contribuir para os estudos da Análise Crítica do Discurso como também da Análise do Discurso Multimodal.

\subsubsection{Valoração}

De acordo com Crystal, a linguagem pode apresentar conotações positivas e/ou negativas, quando expressamos nossos sentimentos e pensamentos. Quando uma/um usuária/o da língua deseja persuadir uma/um outra/o de alguma coisa em detrimento de outra, ela/ele usa de estratégias que podem ser "parciais", a fim de atingir seu propósito comunicativo (Crystal). Além disso, o uso retórico da linguagem também serve para fins persuasivos e todas/os nós utilizamos a retórica em maior ou menor grau (Crystal).

No campo da Linguística Sistêmico-Funcional (Cf. Martin and White; Martin and Rose), o sistema que oferece recursos para a investigação da Atitude, do Comprometimento e da Gradação na linguagem chama-se Valoração. Consoante Martin and White, a Valoração associa-se à metafunção interpessoal e preocupa-se com o modo pelo qual o Afeto, o Julgamento e a Apreciação são manifestados; com quão dialógico um discurso pode ser; e com o grau de intensidade que um enunciado pode apresentar. Ademais, a Valoração é aplicável a diversos Gêneros, inclusive aqueles com estrutura narrativa (Cf. Macken-Horarik and Isaac), desde que estes instanciem significados que suscitem uma interpessoalidade avaliativa. 


\subsubsection{Atitude}

O sistema Atitude compreende os sistemas Afeto, Julgamento e Apreciação (Martin and White; Martin and Rose).

Segundo Martin and White, o sistema Afeto relaciona-se aos sentimentos que temos, sejam eles positivos ou negativos (e.g., "Clarice está triste."). Martin and Rose consideram que o sistema Julgamento refere-se a como ajuizamos os indivíduos: de forma positiva ou negativa; do ponto de vista pessoal ou moral (e.g., "um bom político"). Ademais, conforme Martin and White, o sistema Apreciação associa-se à maneira pela qual valoramos coisas, seja positivamente, seja negativamente (e.g., "um filme ruim"). Por fim, os três sistemas realizam significados que podem ser explícitos ou implícitos e, ainda, que podem ser graduados (Martin and Rose).

\subsubsection{Comprometimento}

O sistema Comprometimento diz respeito aos pontos de vista e aos posicionamentos adotados pelas/os usuárias/os da língua em interações. Quando não existem tais pontos de vista e posicionamentos nos enunciados, o discurso é monoglóssico. Do contrário, o discurso é heteroglóssico. No âmbito da Heteroglossia, esse sistema abarca a Contração e a Expansão. No tocante à Contração, têm-se a refutação e a proclamação. A refutação relaciona-se à negação (e.g., "nunca") e à contraposição (e.g., "embora"). A proclamação refere-se à concordância (e.g., "claro"), à pronunciação (e.g., "de fato") e ao endosso (e.g., "o jornalista mostra que [...]"). Por sua vez, a concordância divide-se em afirmação (e.g., "naturalmente") e concessão (e.g., "de forma admitida"). No que tange à Expansão, têm-se a consideração (e.g., "talvez") e a atribuição, que se desmembra em reconhecimento (e.g., "muitos brasileiros acreditam que [...]") e distanciamento (e.g., "o advogado alegou que [...]") (Martin and White).

Como pode-se perceber, a investigação de diversas vozes respalda-se bem no sistema Comprometimento, proposto pelos autores. 


\subsubsection{Gradação}

O sistema Gradação compreende o Foco e a Força. No tocante ao Foco, pode-se enfocar ou desfocar os significados atitudinais (e.g., "uma cantora de verdade"). No que tange à Força, pode-se aumentá-los ou reduzi-los (e.g., "Que livro maravilhoso!"). Ademais, a Força pode ser realizada mediante intensificadores, o léxico atitudinal, como no exemplo apresentado, metáforas (sob a perspectiva sistêmica) e xingamentos (swearing) (Martin and Rose).

Os sistemas Gradação, Comprometimento e Atitude estabelecem também relação com outras duas categorias valorativas, quais sejam, o Acoplamento (Coupling) a Calibragem (Commitment). Segundo Martin (c), o Acoplamento (Coupling) corresponde à combinação de significados através de estratos e das metafunções, por exemplo. De acordo com o autor, a Calibragem (Commitment) diz respeito a quão específico pode ser o significado instanciado em um dado texto. O autor afirma que essas duas categorias estão relacionadas entre si e que são relevantes na retórica de qualquer Gênero.

Martins busca pesquisar as variações semânticas de Atitude e Comprometimento em trechos dos Estágios de Orientação e Resolução dos contos "The artificial nigger" e "A late encounter with the enemy”, de Flannery O'Connor, e dos Estágios correspondentes de duas Reinstanciações para o português do Brasil, uma de José Roberto O'Shea e a outra de Leonardo Fróes. As orações desses trechos foram alinhadas e, após essa etapa, foram classificadas com categorias dos sistemas já mencionados. Em seguida, foram enfocados os significados atitudinais, levando-se em consideração como tais significados foram construídos do ponto de vista do narrador e das personagens. O autor observa que há variações de Acoplamento atitudinal, gradativo e heteroglóssico, bem como de Calibragem de Gradação. Ademais, Martins também observa que nos textos traduzidos as personagens são caracterizadas de maneira distinta, considerando-se as categorias semântico-discursivas utilizadas.

Magalhães and Dias procuram investigar as variações semânticas de Valoração em passagens de dois romances de Chinua 
Achebe, quais sejam, Things fall apart e Arrow of God, e de suas passagens correspondentes em Reinstanciações para o português europeu, Tudo se desmorona, traduzido por Eugénia Antunes e Paulo Rêgo, e A Flecha de Deus, traduzido por Maria Helena Morbey, a fim de testar a hipótese de retradução elaborada por Berman (apud Magalhães and Dias). Quanto à Atitude, as passagens foram classificadas segundo Macken-Horarik and Isaac, que metodizam os preceitos sobre Valoração, a partir de Martin and White e Martin and Rose (Magalhães and Dias). No que concerne à classificação do Comprometimento e da Gradação nessas passagens, a autora e o autor lançaram mão de Martin e White (2005). Ao cotejar os resultados com aqueles alcançados por Dias (apud Magalhães and Dias), que examinou Reinstanciações desses romances para o português do Brasil, a autora e o autor verificam que existem variações semânticas nos textos traduzidos em relação a como os significados valorativos são ativados, acoplados e calibrados. A autora e o autor também verificam que as Reinstanciações para o português europeu podem ser consideradas "paráfrases" diferentes, na concepção bermaniana, visto que as mesmas encontram-se mais distantes dos seus respectivos Textos Fontes, o que corrobora a hipótese de retradução.

\subsection{Adjuntos Modais}

Os Adjuntos Modais são categorias interpessoais pertencentes à léxico-gramática hallidayana que se manifestam por intermédio de advérbios e sintagmas preposicionados (Eggins). Essas categorias podem ser de Modo Oracional ou de Comentário: no primeiro caso, o Adjunto Modal está mais vinculado ao Sujeito Gramatical e ao Finito que no segundo caso (Halliday). Porém, algumas/alguns autoras/autores defendem que os Adjuntos Modais de Comentário não incidem no Modo Oracional, como Eggins, por exemplo.

Muitos Adjuntos Modais contribuem para a tecitura de significados valorativos. A título de exemplificação, os Adjuntos Modais de Modo Oracional de Intensidade, como "até mesmo" e "somente", 
colaboram para sinalizar uma contra-expectativa, o que repercute no sistema Comprometimento. Além disso, como já mencionado, "nunca" é um Adjunto Modal de Modo Oracional de Usualidade que também tem impacto nesse sistema. Ademais, os Adjuntos Modais de Modo Oracional de Grau, como "muito" e "quase", estão relacionados ao sistema Gradação. Finalmente, os Adjuntos Modais de Comentário de Opinião, como "de acordo com [...]", impactam no sistema Comprometimento. Mais especificamente, enquadram-se no sistema Expansão, seguido do sistema de atribuição do tipo reconhecimento (Halliday; Martin and White).

Diante do exposto, pode-se observar o elo entre a léxico-gramática e a semântica do discurso.

Rodrigues-Júnior e Barbara têm por objetivo averiguar a Valoração do romance The Picture of Dorian Gray, de Oscar Wilde, de uma de suas traduções para o português do Brasil, realizada por João do Rio, bem como de duas de suas adaptações, uma feita por Clarice Lispector e a outra por Cláudia Lopes, no tocante à representação dos personagens gays das narrativas. $\mathrm{O}$ autor e a autora enfocam a voz do narrador, seja mediante orações verbais projetantes, seja por meio do ponto de vista narrativo e dos diálogos das personagens. Foi utilizada a ferramenta Aligner do programa computacional WordSmith Tools a fim de selecionar os trechos a serem analisados (Rodrigues-Júnior and Barbara). Na seleção, foram encontradas 92 projeções com Processos Verbais, das quais 10 foram escolhidas, por serem representativas de padrões valorativos do Texto Fonte (Rodrigues-Júnior and Barbara). No que concerne aos Adjuntos Modais, o autor e a autora assinalam que essas categorias tornam-se importantes para "enriquecer" os diálogos e identificar componentes dos sistemas Atitude e Comprometimento nos textos em relação de tradução. Rodrigues-Júnior and Barbara constatam que os estudos de corpora não se relacionam somente a equivalências tradutórias, mas também a questões de recriação e de reescrita.

A seguir são explanados os critérios metodológicos empregados neste artigo. 


\section{Metodologia}

Esta seção fornece informações acerca do corpus utilizado assim como dos procedimentos de análise adotados para, juntamente com o Referencial Teórico, propiciar os Resultados e Discussão deste artigo.

\subsection{O Corpus}

Foram escolhidos o conto "Grace" de James Joyce (2001) e duas de suas Reinstanciações para o português do Brasil, uma de José Roberto O'Shea (Joyce b) e a outra de Guilherme da Silva Braga (Joyce c). Além da arte verbal presente nos contos, houve ainda uma outra motivação para escolhê-los, qual seja, esses contos não são nem muito curtos e nem muito longos, perfazendo aproximadamente 24.000 palavras. Isso viabilizou a análise no período de tempo estipulado.

"Grace" (Joyce a), "Graça" (Joyce b) e "Graça" (Joyce c) contam a história de um caixeiro-viajante, o sr Kernan, que se convertera ao catolicismo por ocasião do seu casamento. O sr Kernan é alcoolista e tal fato motiva seus amigos a ajudá-lo, por intermédio de artifícios religiosos, quando propõem a ele um retiro espiritual. A fim de convencê-lo disso, questões de religião são discutidas através de inúmeros diálogos retratados nos contos. No desfecho dos contos, tais questões parecem encontrar resposta, o que espalha esperança em sr Kernan e seus amigos.

Em 2012, O'Shea apresenta ao público uma nova tradução de Dubliners, coletânea de contos de Joyce, na qual se encontra o conto "Grace". O tradutor avisa que o cuidado com questões de estilo permaneceu o mesmo, porém a experiência adquirida como tradutor literário e o acesso a novas fontes de consulta levaram-no a fazer retificações para essa nova tradução. O'Shea considera que a polifonia é um traço estilístico marcante de Joyce e, diante dessa consideração, salienta que os "erros" gramaticais e ortográficos nas falas de certas personagens no Texto Traduzido são intencionais. Esses

Cad. Trad., Florianópolis, v. 39, no 3, p. 249-271, set-dez, 2019. 
"erros" no Texto Fonte causam um efeito estético relacionado à Heteroglossia como tratam também de particularidades socioculturais das personagens (O'Shea). Segundo o tradutor, "Grace” é um dos contos de Dubliners em que esses "erros" se manifestam.

Sobre a experiência de traduzir Dubliners para o português do Brasil, o tradutor Guilherme da Silva Braga (2012) relata que foi uma grande responsabilidade, tendo em vista o prestígio acadêmico de James Joyce e o público-alvo, que poderia ser formado por especialistas em Letras. Ademais, o tradutor assinala que seu texto traduzido não apresenta notas, o que não "condiciona" quem está lendo Dublinenses pela primeira vez. ${ }^{1}$

\subsection{Procedimentos de Análise}

Em um outro momento, os Adjuntos Modais dos contos foram identificados e classificados. Posteriormente, as sentenças com esses Adjuntos Modais foram compiladas para uma planilha XSL. Foi adotado o conceito grafológico de sentença proposto por Halliday and Matthiessen (2014). De acordo com esse conceito, a sentença inicia-se com uma letra maiúscula e termina com um ponto final ou com ponto de interrogação ou com um ponto de exclamação.

A planilha eletrônica apresenta 3 abas, uma para cada conto. No topo de cada aba, no sentido horizontal, foram consideradas as categorias Afeto, Julgamento e Apreciação para o sistema Atitude; as categorias Monoglóssico e Heteroglóssico para o sistema Comprometimento; e as categorias Foco e Força para o sistema Gradação. No sentido vertical, levando em conta a primeira coluna, foram alocadas as sentenças com os Adjuntos Modais. Para cada sentença, nas células do programa computacional Excel da plataforma Windows, colocou-se "S" para "sim", quando houve ocorrência de uma categoria valorativa, ou "N" para "não",

https://www.lpm.com.br/site/default.asp?TroncoID = 805133\&SecaoID = $816261 \&$ SubsecaoID $=618848 \&$ Template $=.$. /artigosnoticias/user_exibir . asp\&ID $=636311$

Cad. Trad., Florianópolis, v. 39, nº 3, p. 249-271, set-dez, 2019. 
quando não ocorreu. Como já observado, muitos Adjuntos Modais estão relacionados à Valoração. Destarte, muitas sentenças receberam " $\mathrm{S}$ " em alguma categoria em função disso. Contudo, a Valoração pode manifestar-se em outros itens lexicais, ou seja, para este artigo, bastou que ocorresse uma manifestação de Afeto em um grupo nominal, por exemplo, para que a sentença recebesse o código " $\mathrm{S}$ ". E, caso houvesse mais ocorrências dessa categoria, permaneceria também esse código.

Assim, a quantificação foi relativizada, não havendo classificação de item por item, o que oferece uma visão global dos dados. Cabe mencionar que para gerar os dados quantitativos foram usadas funções do programa computacional Excel da plataforma Windows, conforme sugestão de Alves and Assis. Para este artigo, a título de exemplificação, no que concerne à categoria Afeto, no Texto Fonte, a função foi = COUNTIF(B2:B196, "S”). "B2:B196" compreende o intervalo ao passo que " $\mathrm{S}$ " relaciona-se ao critério, isto é, o que é para ser quantificado. Desse modo, foi possível calcular quantas vezes a categoria Afeto foi realizada. Alves and Assis afirmam que a/o pesquisadora/pesquisador pode inserir a função diretamente no campo adequado ou utilizar o assistente de funções.

São mostrados em seguida os Resultados e a Discussão deste trabalho.

\section{Resultados e Discussão}

Baseada em uma das perspectivas dos Estudos da Tradução com interface na Linguística Sistêmico-Funcional e nos procedimentos metodológicos adotados, esta seção traz os dados quantitativos obtidos e exemplos do corpus, discutidos de forma intercalada. TF corresponde ao Texto Fonte em inglês de Joyce (2001); RI1 à Reinstanciação Interlinguística de O'Shea (Joyce b); e, por fim, RI2 à Reinstanciação Interlinguística de Braga (Joyce c). A TAB. 1 pode ser verificada em seguida. 
Tabela 1: Atitude nas sentenças com Adjuntos Modais

\begin{tabular}{l|l|l|l}
\hline & TF & RI1 & RI2 \\
\hline Afeto & 38 & 36 & 45 \\
\hline Julgamento & 135 & 132 & 121 \\
\hline Apreciação & 60 & 55 & 71 \\
\hline TOTAL & 233 & 223 & 237 \\
\hline
\end{tabular}

Fonte: elaboração de minha autoria.

A TAB. 1 mostra que as sentenças com Adjuntos Modais realizam os 3 sistemas atitudinais, quais sejam, Afeto, Julgamento e Apreciação. O sistema mais solicitado é o de Julgamento. Isso significa que o narrador e as personagens predominantemente fazem juízo de valor, não expondo com tanta frequência sentimentos acerca de figuras humanas e considerações sobre coisas.

Conforme a TAB. 1, a RI1 realiza em menor grau os sistemas Afeto, Julgamento e Apreciação, em comparação ao TF. Tal dado indica que a RI1 é menos atitudinal que o TF do ponto de vista valorativo no âmbito das sentenças com Adjuntos Modais. Além disso, a RI2 realiza em maior grau os sistemas Afeto e Apreciação, e em menor grau o sistema Julgamento, se comparado ao TF. Diferentemente de O'Shea, Braga "acentua" os sistemas Afeto e Apreciação, o que pode levar a variações semânticas. Finalmente, a RI2 apresenta menos ocorrências do sistema Julgamento e mais ocorrências dos sistemas Afeto e Apreciação, em cotejo com a RI1 e o TF. Se por um lado, as sentenças com Adjuntos Modais de Braga são mais afetivas e apreciativas, por outro lado, faltariam a estas mais teor de Julgamento.

Rodrigues-Júnior and Barbara (2013) consideram que os Adjuntos Modais contribuem para detectar significados atitudinais de textos literários, o que pode ser confirmado pelos dados quantitativos da TAB. 1.

A TAB. 2 pode ser vista a seguir. 
Tabela 2: Comprometimento nas sentenças com Adjuntos Modais

\begin{tabular}{l|l|l|l}
\hline & TF & RI1 & RI2 \\
\hline Monoglóssicas & 22 & 16 & 19 \\
\hline Heteroglóssicas & 173 & 171 & 168 \\
\hline TOTAL & 195 & 187 & 187 \\
\hline
\end{tabular}

Fonte: elaboração de minha autoria.

A TAB. 2 aponta que a Heteroglossia é predominante no corpus. Isso revela que recursos heteroglóssicos, tais como, projeção, concessão e modalidade, dentre outros (Martin and White; Martin and Rose) são utilizados para abarcar vozes adicionais nas sentenças com Adjuntos Modais. Como já mencionado, muitos destes últimos já contribuem para os significados de Comprometimento, o que também é apontado por Rodrigues-Júnior and Barbara (2013).

De acordo com a TAB. 2, e em termos absolutos, o TF é mais heteroglóssico que a RI1 e a RI2. Ademais, a RI2 é mais monoglóssica e menos heteroglóssica que a RI1. Considerando as sentenças com Adjuntos Modais, O'Shea lança mão de recursos heteroglóssicos com mais frequência que Braga.

Pode-se observar também que O'Shea considera o conto "Grace" polifônico. Tal fato pode ser estendido às traduções e está em consonância com os dados quantitativos mostrados na TAB. 2, uma vez que o TF, a RI1 e a RI2 apresentam principalmente ocorrências de Heteroglossia.

A TAB. 3 pode ser observada em seguida.

Tabela 3: Gradação nas sentenças com Adjuntos Modais

\begin{tabular}{l|l|l|l}
\hline & TF & RI1 & RI2 \\
\hline Foco & 15 & 10 & 10 \\
\hline Força & 89 & 59 & 65 \\
\hline TOTAL & 104 & 69 & 75 \\
\hline
\end{tabular}

Fonte: elaboração de minha autoria.

Cad. Trad., Florianópolis, v. 39, no 3, p. 249-271, set-dez, 2019. 
Pode-se perceber pela TAB. 3 que o sistema Força é realizado mais frequentemente que o sistema Foco nas sentenças com Adjuntos Modais. Isso é sinal de que os significados atitudinais são mais aumentados ou reduzidos que enfocados ou desfocados no corpus.

Consoante a TAB. 3, tanto a RI1 como a RI2 apresentam menos ocorrências de Foco e Força em cotejo com o TF. Isso demonstra que o TF é mais gradativo que as Reinstanciações Interlinguísticas, o que pode ter impacto em questões de Acoplamento e Calibragem no corpus (Cf. Martins; Magalhães and Dias). Comparando-se a RI1 e a RI2, observa-se que as realizações de Foco são iguais e que as de Força são diferentes, sendo que na RI2 estas últimas são mais frequentes que na RI1. Isso sinaliza que Braga faz mais uso do sistema gradativo Força em comparação a O'Shea.

Os exemplos a seguir são descritos e analisados. Os Adjuntos Modais encontram-se em itálico.

\section{Exemplo 1:}

TF:

He had never been seen in the city without a silk hat of some decency and a pair of gaiters.

RI1 (O'Shea):

Jamais era visto na cidade sem um chapéu de seda decente e polainas.

RI2 (Braga):

Nunca tinha aparecido na cidade sem um chapéu de seda decente e um par de perneiras.

As 3 orações do Exemplo 1 referem-se ao protagonista, sr Kernan. Essas orações realizam Apreciação positiva e explícita nos seguintes trechos: without a silk hat of some decency (TF) e "sem um chapéu de seda decente" (RI1 e RI2), uma vez que o chapéu é avaliado. Os Adjuntos Modais never (TF), "Jamais" (RI1) e "Nunca" 
(RI2) são recursos heteroglóssicos que contribuem para o Comprometimento das orações. Por fim, não há realização de Gradação.

Exemplo 2:

TF:

'I'm so sorry,' she continued, 'that I've nothing in the house to offer you.

RI1 (O'Shea):

-- Desculpe -- ela continuou --, mas eu não tenho nada em casa pra oferecer pro senhor.

RI2 (Braga):

-- Me desculpe, continuou a sra Kernan, mas eu não tenho nada em casa para oferecer.

No Exemplo 2, a sentença do TF instancia Força em so sorry, o que torna mais intensificado o Afeto negativo e explícito da sra Kernan. Tal significado gradativo não é reinstanciado nas RI1 e RI2, fazendo que o Afeto não seja aumentado. As três sentenças do Exemplo 2 estão condizentes com a TAB. 3, uma vez que instâncias do sistema Força são mais frequentes no TF que nas Reinstanciações Interlinguísticas. Ademais, há Apreciação negativa e explícita nos itens lexicais nothing (TF) e "nada" (RI1 e RI2), que sinalizam a escassez de recursos da residência dos Kernan. Finalmente, nas sentenças do Exemplo 2, o Comprometimento se dá mediante projeções e negações, configurando assim um discurso heteroglóssico.

\section{Exemplo 3:}

TF:

They were good sons, wrote regularly and sometimes sent home money. 


\section{RI1 (O'Shea):}

Eram bons filhos; escreviam com frequência e às vezes mandavam dinheiro para casa.

RI2 (Braga):

Eram bons filhos, escreviam regularmente e às vezes mandavam dinheiro para casa.

Os filhos referidos no Exemplo 3 são da sra Kernan e do sr Kernan. Trata-se dos filhos mais velhos que já são independentes. Nas sentenças do Exemplo 3, há instâncias de Julgamento positivo e explícito desses filhos por intermédio dos Epítetos Atitudinais (Halliday) good (TF) e "bons" (RI1 e RI2). Além disso, o Comprometimento é realizado por meio dos Adjuntos Modais sometimes (TF) e "às vezes" (RI1 e RI2). Por fim, nenhum significado de Atitude é enfocado/desfocado e/ou aumentado/reduzido nas sentenças do Exemplo 3.

\section{Exemplo 4:}

TF:

It's not exactly a sermon, you know.

RI1 (O'Shea):

Não se trata propriamente de pregação, você sabe.

RI2 (Braga):

Não é bem um sermão, sabe?

As sentenças do Exemplo 4 referem-se a falas do sr Cunningham, amigo do sr Kernan, que indicam realização de heteroglossia, visto que são orações projetadas. As primeiras orações das sentenças do Exemplo 4 realizam Apreciação negativa e explícita do sermon (TF), da "pregação" (RI1) e do "sermão" (RI2) com Foco do tipo "Desfoque" através das negações e dos Adjuntos Modais exactly (TF), "propriamente" (RI1) e "bem" (RI2). 
Exemplo 5:

TF:

'And yet they say he wasn't much of a theologian,' said Mr Cunningham.

RI1 (O'Shea):

-- E há quem diga que ele não era um grande teólogo -disse Mr Cunningham.

RI2 (Braga):

-- E mesmo assim dizem que ele não era um teólogo lá muito bom, disse o sr Cunningham.

Novamente, temos falas do sr Cunningham com orações projetantes e projetadas, o que configura heteroglossia. Ademais, o Julgamento das sentenças do TF, da RI1 e da RI2 é negativo e explícito, Julgamento esse feito em relação a um teólogo. O sistema Força realiza-se através dos Adjuntos Modais much (TF) e "muito" (RI2). O'Shea opta por realizar esse sistema mediante o Epíteto Atitudinal (Halliday) "grande".

Procede-se às Considerações Finais deste artigo.

\section{Considerações Finais}

Como visto anteriormente, Rodrigues-Júnior and Barbara afirmam que os Adjuntos Modais são úteis para a identificação de significados atitudinais e de Comprometimento em textos literários. Este artigo mostrou que, além desses significados, os Adjuntos Modais também são relevantes para a detecção de significados de Gradação.

Nas sentenças com Adjuntos Modais dos contos, o Julgamento, a Heteroglossia e a Força constituem os sistemas mais solicitados. Quanto ao sistema Atitude, destaca-se a RI2, por realizar em maior grau significados afetivos e apreciativos. Quanto ao sistema Comprometimento, realça-se a RI1, por apresentar mais ocorrências 
heteroglóssicas em comparação à RI2. Por fim, quanto ao sistema Gradação, ressalta-se a RI2, por ser mais gradativa que a RI1.

O'Shea aponta que a questão teórica e prática mais contundente dos Estudos da Tradução é quão próxima ou distante uma tradução pode ser do original. Mediante os dados quantitativos deste artigo, pode-se observar que, considerando as sentenças com Adjuntos Modais, que a RI1 e a RI2 são relativamente mais próximas do TF do ponto de vista atitudinal e heteroglóssico e são mais distantes do ponto de vista gradativo. Em outras palavras, a proximidade deve-se à maior semelhança desses dados entre os Textos Traduzidos e o Texto Fonte; e a distância deve-se à maior dissimilitude entre eles. Isso demonstra que pode haver proximidade ou distanciamento das traduções em relação ao original em diferentes trechos dos textos envolvidos.

Pode-se afirmar que Martins está mais vinculado teórica-metodologicamente a Martin que Rodrigues-Júnior and Barbara, pois, além de fazer uso do conceito de Valoração, Martins usa também o conceito de Estágios (Cf. Martin and Rose), que não é utilizado por Rodrigues-Júnior and Barbara. De forma alternativa, ao investigar a Valoração, Rodrigues-Júnior and Barbara optam pela Linguística de Corpus como método. Apesar de Magalhães and Dias não mencionarem Estágios em seu trabalho, este está amplamente relacionado a Dias, que utiliza esse conceito. Tanto Martins como Magalhães and Dias adotam o conceito de Reinstanciação Interlinguística, proposto por Souza (c), conceito esse também adotado neste artigo. Metodologicamente, este artigo aproxima-se mais de Rodrigues-Júnior and Barbara, e, teoricamente, está mais próximo de Martins e Magalhães and Dias. Isso demonstra que o presente trabalho defende diferentes pontos de vista de temas semelhantes.

Espera-se que este artigo ${ }^{2}$ possa ter contribuído com mais conhecimentos acerca de textos literários em relação de tradução a partir de uma visão linguístico-discursiva com apoio dos Estudos da Tradução direcionados à Literatura.

\footnotetext{
${ }^{2}$ Agradeço ao doutorando Cliver Dias por ocasião da discussão sobre a classificação da Valoração nas sentenças com Adjuntos Modais.
}

Cad. Trad., Florianópolis, v. 39, no 3, p. 249-271, set-dez, 2019. 


\section{Referências}

Alves, D. A. S. e Assis, R. C. "Métodos de investigação em corpora: Ferramentas para classificação de dados extraídos de corpora de pequenas dimensões para análises discursivas." In: Escola Brasileira de Linguística Computacional, 8 \& Encontro De Linguística De Corpus, 13, 2015, João Pessoa. Anais... João Pessoa: UFPB, 2016, p. 1- 17.

Braga, G. S. O tradutor de Dublinenses fala sobre tradução e James Joyce. Entrevista concedida a LP\&M EDITORES, 2012. Disponível em: < https:// www.lpm.com.br/site/default.asp? TroncoID $=805133 \&$ SecaoID $=816261 \&$ Subs ecaoID $=618848 \&$ Template $=. . /$ artigosnoticias/user_exibir. asp $\& I D=636311>$.

Crystal, D. A little book of language. New Haven/London: Yale University Press, 2011.

Dias, C. G. Valoração e Variações Semânticas: um estudo das reinstanciações de estágios discursivos de Things Fall Apart e Arrow of God. 2018. 150 f. Dissertação (Mestrado em Linguística Aplicada) - Faculdade de Letras, Universidade Federal de Minas Gerais, 2018.

Eggins, S. An introduction to systemic functional linguistics. London/New York: Continuum, 2004.

Halliday, M. A. K. An introduction to functional grammar. 2. ed. London/New York: Edward Arnold, 1994.

Halliday; M. A. K. e Matthiessen, C. M. I. M. Halliday's introduction to functional grammar. 4. ed. London/New York: Routledge, 2014.

Hood, S. Summary writing in academic contexts: implicating meaning in processes of change. Linguistics and Education, n. 19, p. 351-365, 2008.

Joyce, J. (a). "Grace". In: Joyce, J. Dubliners. Ware: Wordsworth Editions, 2001. 
Joyce, J. (b). "Graça”. In: Joyce, J. Dublinenses. Tradução de José Roberto O’Shea. São Paulo: Editora Hedra, 2012.

Joyce, J. (c). "Graça”. In: Joyce, J. Dublinenses. Tradução de Guilherme da Silva Braga. Porto Alegre: L\&PM Editores, 2013.

Macken-Horarik, M. e Isaac, A. “Appraising Appraisal”. In: Thompson, G; AlbaJuez, L. (ed.) Evaluation in context. Amsterdam/Philadelphia: John Benjamins Publishing Company, p. 67-92, 2014.

Magalhães, C. M. e Dias, G. C. Variações semânticas de valoração em reinstanciações portuguesas e brasileiras Things fall apart e Arrow of God. Cadernos de Tradução (UFSC) 38.3 (2018): 319-351.

Martin, J. R. (a). English text: system and structure. Amsterdam/Philadelphia: John Benjamins, 1992.

Martin, J. R. (b). "Innocence: realisation, instantiation and individuation in a Botswanan town." In: Knight, N. e Mahboob, A. (ed.) Questioning Linguistics. Cambridge: Cambridge Scholars Publishing, p. 27-54, 2008.

Martin, J. R. (c). "Semantic variation - modeling realization, instantiation and individuation in social semiosis." In: Bednarek, M.; Martin, J. R. New discourse on language: functional perspectives on multimodality, identity, and affiliation. London/New York: Continuum, p. 1-34, 2010.

Martin, J. R. (d) “The Discourse Semantics of Attitudinal Relations: continuing the study of lexis." Russian Journal of Linguistics 21.1, 2017.

Martin, J. R. e Rose, D. Working with discourse: meaning beyond the clause. London/New York: Continuum, 2007.

Martin, J. R. e White, P. R. R. The language of evaluation: appraisal in English. Basingstoke/New York: Palgrave Macmillan, 2005.

Martins, A. E. Valoração e Variações Semânticas: um estudo sobre duas reinstanciações para o português de $A$ late encounter with the enemy $e$ The 
artificial nigger. 2018. 160f. Dissertação (Mestrado em Linguística Aplicada Faculdade de Letras, Universidade Federal de Minas Gerais.

O’Shea, J. R. “Introdução”. In: Joyce, J. Dublinenses. Tradução de José Roberto O’Shea. São Paulo: Editora Hedra, p. 7-17, 2012.

Rodrigues, R. R. Valoração em contos de James Joyce e em duas de suas traduções para o português do Brasil sob a ótica dos Adjuntos Modais. 2017. 16f. Projeto de Pesquisa (Pós-doutorado em Linguística Aplicada) - Centro de Letras e Comunicação, Universidade Federal de Pelotas.

Rodrigues-Júnior, S. A.; Barbara, L. "Linguistic constructions of appraisal in the novel The Picture of Dorian Gray and its Brazilian translation and adaptations: an exploratory analysis." RBLA 13.1, 2013: 259-285.

Souza, L. M. F. (a). "A tradução de termos de recentes desenvolvimentos da linguística sistêmico-funcional para o português brasileiro." Tradução \& Comunicação: Revista Brasileira de Tradutores, n. 22, 2011: 73-90.

Souza, L. M. F. (b). "Interlingual re-instantiation - a new systemic functional perspective on translation.” Text\&Talk 33(4-5), 2013: 575-594.

Recebido em: 22/04/2019

Aceito em: 18/07/2019

Publicado em: Setembro de 2019

Roberta Rego Rodrigues. E-mail: betareseau@gmail.com.

ORCID: https://orcid.org/0000-0002-1580-1789 